\title{
Blood DNA methylation and breast cancer risk: a meta-analysis of four prospective cohort studies
}

Clara Bodelon ${ }^{1 *+}$, Srikant Ambatipudi ${ }^{2,3 \dagger}$, Pierre-Antoine Dugué ${ }^{4,5+}$, Annelie Johansson ${ }^{6 \dagger}$, Joshua N. Sampson ${ }^{1}$, Belynda Hicks ${ }^{1,7}$, Eric Karlins ${ }^{1,7}$, Amy Hutchinson ${ }^{1,7}$, Cyrille Cuenin ${ }^{2}$, Veronique Chajès ${ }^{2}$, Melissa C. Southey ${ }^{8}$, Isabelle Romieu2, Graham G. Giles ${ }^{4,5}$, Dallas English ${ }^{4,5}$, Silvia Polidoro9,10, Manuela Assumma ${ }^{9,10}$, Laura Baglietto ${ }^{11}$, Paolo Vineis ${ }^{12}$, Gianluca Severi ${ }^{13}$, Zdenko Herceg ${ }^{2+}$, James M. Flanagan ${ }^{6 \dagger}$, Roger L. Milne ${ }^{4,5+}$ and Montserrat Garcia-Closas ${ }^{1+}$

\begin{abstract}
Background: Environmental and genetic factors play an important role in the etiology of breast cancer. Several small blood-based DNA methylation studies have reported risk associations with methylation at individual CpGs and average methylation levels; however, these findings require validation in larger prospective cohort studies. To investigate the role of blood DNA methylation on breast cancer risk, we conducted a meta-analysis of four prospective cohort studies, including a total of 1663 incident cases and 1885 controls, the largest study of blood DNA methylation and breast cancer risk to date.
\end{abstract}

Methods: We assessed associations with methylation at 365,145 CpGs present in the HumanMethylation450 (HM450K) Beadchip, after excluding CpGs that did not pass quality controls in all studies. Each of the four cohorts estimated odds ratios (ORs) and 95\% confidence intervals (Cl) for the association between each individual CpG and breast cancer risk. In addition, each study assessed the association between average methylation measures and breast cancer risk, adjusted and unadjusted for cell-type composition. Study-specific ORs were combined using fixed-effect meta-analysis with inverse variance weights. Stratified analyses were conducted by age at diagnosis $(<50, \geq 50)$, estrogen receptor (ER) status ( $+/-)$, and time since blood collection $(<5,5-10,>10$ years). The false discovery rate ( $q$ value) was used to account for multiple testing.

Results: The average age at blood draw ranged from 52.2 to 62.2 years across the four cohorts. Median follow-up time ranged from 6.6 to 8.4 years. The methylation measured at individual CpGs was not associated with breast cancer risk ( $q$ value $>0.59$ ). In addition, higher average methylation level was not associated with risk of breast cancer $(\mathrm{OR}=0.94,95 \% \mathrm{Cl}=0.85,1.05 ; P=0.26$; $P$ for study heterogeneity $=0.86)$. We found no evidence of modification of this association by age at diagnosis $(P=0.17)$, ER status $(P=0.88)$, time since blood collection $(P=0.98)$, or $C p G$ location $(P=0.98)$.

(Continued on next page)

\footnotetext{
*Correspondence: clara.bodelon@nih.gov

${ }^{\dagger}$ Clara Bodelon, Srikant Ambatipudi, Pierre-Antoine Dugué, and Annelie Johansson are co-first authors.

Zdenko Herceg, James M. Flanagan, Roger L. Milne, and Montserrat Garcia-

Closas are co-last authors.

'Divison of Cancer Epidemiology and Genetics, National Cancer Institute,

Bethesda, USA

Full list of author information is available at the end of the article
}

(c) The Author(s). 2019 Open Access This article is distributed under the terms of the Creative Commons Attribution 4.0 International License (http://creativecommons.org/licenses/by/4.0/), which permits unrestricted use, distribution, and reproduction in any medium, provided you give appropriate credit to the original author(s) and the source, provide a link to the Creative Commons license, and indicate if changes were made. The Creative Commons Public Domain Dedication waiver (http://creativecommons.org/publicdomain/zero/1.0/) applies to the data made available in this article, unless otherwise stated. 
(Continued from previous page)

Conclusions: Our data indicate that DNA methylation measured in the blood prior to breast cancer diagnosis in predominantly postmenopausal women is unlikely to be associated with substantial breast cancer risk on the HM450K array. Larger studies or with greater methylation coverage are needed to determine if associations exist between blood DNA methylation and breast cancer risk.

Keywords: Breast cancer risk, Blood DNA methylation, Prospective study, Meta-analysis

\section{Introduction}

There are many well-established environmental and genetic factors associated with breast cancer risk but whether DNA methylation measured in blood is associated with breast cancer risk remains to be determined. The rationale for such an association is that blood DNA methylation levels could be a surrogate for breast tissue methylation [1-4], represent immunity/inflammation at the target tissue itself, indicate altered molecular pathways involved in carcinogenesis, or reflect past endogenous or exogenous exposures such as hormone levels [5, 6], alcohol [7], body mass index (BMI) [8, 9], smoking $[10,11]$, or ionizing radiation [12]. To better understand the possible relationship between blood DNA methylation and breast cancer risk, large, prospective studies with good exposure information and blood samples collected prior to diagnosis are needed.

Evidence for an association between blood-based DNA methylation and breast cancer risk is inconsistent [13]. A recent systematic review summarized the most promising findings of DNA methylation as a biomarker of disease [14], concluding that hypermethylation at BRCA1 and RASSF1A gene promoters, and hypermethylation of the body of the ATM gene were more common in breast cancer cases [1-4, 15-21]. An analysis published after the systematic review reported CpG sites cg06418238 in RPTOR, cg00736299 in MGRN1, and cg27466532 in RAPSN to be more commonly hypomethylated in breast cancer cases [22], although these associations were not replicated by the Melbourne Collaborative Cohort Study (MCCS) [23-25]. A nested case-control study (298 cases and 612 controls) within the Sister Study [26] reported that methylation level at $250 \mathrm{CpG}$ sites of the $27 \mathrm{~K}$ methylation array was associated with breast cancer. Global methylation refers to the total level of 5 -methylcytosine $(5 \mathrm{mC})$ content in a sample relative to total cytosine [27] and global hypomethylation has been related to genomic instability and cancer development $[9,28]$. This global measure has also been investigated as a potential biomarker for breast cancer risk, producing inconsistent findings $[14,29]$. This could be partly explained by the use of different technologies and proxies to measure global methylation [27]. Most recently, methylation arrays have been used to measure selected methylation sites across the genome, and some studies have analyzed the average methylation across these sites as a surrogate measure of global methylation. Using this measure of global methylation derived for the HumanMethylation 450 BeadChip array, two prospective studies, the MCCS [23] and the Italian cohort of the European Prospective Investigation into Cancer and Nutrition (EPIC-Italy) [30], reported that lower global methylation levels in blood DNA were associated with a higher risk of breast cancer. However, this association was not observed by the Norwegian Women and Cancer (NOWAC) study [30].

In this study, we examined the association between DNA methylation in blood and breast cancer risk in the largest to-date study, involving 1663 incident invasive breast cancer cases and 1885 controls combined from four prospective cohort studies.

\section{Methods}

We combined results from four prospective studies: the MCCS [23], EPIC-Italy [30], the IARC cohort of the European Prospective Investigation into Cancer and Nutrition (EPIC-IARC) [31], and the Prostate, Lung, Colorectal, and Ovarian Cancer Screening Trial (PLCO) [32]. Details of the four cohorts and the case-control studies nested therein can be found in Additional file 1: Supplemental Note.

\section{Methylation array}

Three of the cohorts (MCCS, EPIC-Italy, EPIC-IARC) measured DNA methylation using the Illumina Infinium HumanMethylation450 BeadChip (HM450K) array while PLCO used the MethylationEPIC BeadChip, which includes $90 \%$ of the sites in the HM450K array [33]. The four studies processed methylation data using the same protocol. Raw intensity data were imported into the $R$ programming software using the minfi Bioconductor package [34]. Data were pre-processed for background subtraction and control normalization using the preprocessIllumina function. Subset-quantile within array normalization (SWAN) was performed to correct for type I and II probe bias [35]. Each study excluded samples for which more than $5 \%$ of CpG sites had a detection $P$ value $>0.01$. Also, each study excluded CpGs with 
a $P$ value $>0.01$ in more than $20 \%$ of the samples, and CpGs labeled as cross-reactive [36, 37], or located on the $\mathrm{Y}$ chromosome. The meta-analysis was performed on the 365,145 included CpGs common to the four studies. Beta values were used for analysis.

\section{Statistical analysis}

The four studies individually performed conditional (MCCS, EPIC-Italy, EPIC-IARC) or unconditional (PLCO) logistic regression to estimate the odds ratio (OR) and associated standard error (SE) per one standard deviation increase in methylation for each of the 365,145 CpG probes, adjusting where appropriate for the matching variables specific to each study (see Additional file 1: Supplemental Note), cell-type proportions estimated with the Houseman algorithm (percentage $\mathrm{CD} 8 \mathrm{~T}+, \mathrm{CD} 4 \mathrm{~T}+, \mathrm{NK}, \mathrm{B}$ cell, monocytes, granulocytes) [38], and other variables to account for batch effects, such as plate or surrogate variable analysis (SVA) [39, 40]. These analyses within each study were repeated for subsets of individuals defined by the following case characteristics: age at diagnosis $(<50, \geq 50$ years old), estrogen receptor (ER) status (ER+/-), stage (early and late, see Additional file 1: Supplemental Note; associations with individual $\mathrm{CpG}$ probes were done in the PLCO only) and time since from blood collection ( $<2$ years, $\geq$ 2 years; < $5,5-10,>10$ years). Estimates of the pooled ORs and their associated SE were calculated using fixed-effects meta-analysis. The Wald test was used to calculate $P$ values. Statistical significance was defined by a false discovery rate (FDR)-adjusted $P$ value, or $q$ value, less than 0.05 , which means that $5 \%$ of significant tests (i.e., tests with $q<0.05$ ) were expected to be false positives. Heterogeneity in the odds ratio across studies or subgroups was assessed using the $I^{2}$ statistic and the $P$ value for the Cochran's $Q$ statistic.

To assess enrichment at specific genomic regions, we considered the average of the ORs for the CpGs located in those regions. We defined the average $\log (\mathrm{OR}), \beta_{\text {avg }}$, by $\beta_{\text {avg }}=\frac{1}{\mathrm{~K}} \sum \beta_{k}$ and approximated its standard error, $\mathrm{SE}_{\mathrm{avg}}$, by $\mathrm{SE}_{\mathrm{avg}}=\frac{1}{K^{2}} w^{T} \Phi \theta \Phi w$, where $K$ is the number of CpGs in the region of interest, $\beta_{k}$ and $\sigma_{k}$ the estimated $\log (\mathrm{OR})$, and SE for probe $k, \theta$ the $K \times K$ correlation matrix of the $K$ probes among controls, $\Phi$ the $K \times K$ diagonal matrix with the SEs along the diagonal and $w$ a column vector of values equal to 1 . We then report $\exp \left(\beta_{\text {avg }}\right)$ as the average OR and calculate the $95 \%$ confidence interval under normality assumption and $P$ values using the Wald test.

Each of the four studies also performed adjusted logistic regression to assess the association between a one standard deviation increase in global DNA methylation and the risk of breast cancer. Global methylation was defined for each study participant as the average methylation level across all 365,145 CpGs. In addition, we computed average measures in CpG islands, CpG shores, CpG shelves, and "open sea," as well as at regulatory regions defined using the UCSC classification (promoter, gene body, 3' UTR or intergenic) [41]. CpG sites were considered to be in a promoter region if they were located within $1500 \mathrm{bp}$ of the transcription start site (TSS), in the 5'UTR or in the first exon [41].

All analyses were conducted using the $\mathrm{R}$ software, version 3.4.1.

\section{Results}

The characteristics of the 1663 cases and 1885 controls included in the meta-analysis are described in Table 1.

\section{Associations between individual CpG sites and breast cancer risk}

We found no evidence of association between blood DNA methylation measured at individual CpG sites and breast cancer risk (Fig. 1, $q>0.59$ ) overall, or after stratification by age $(<50,>50$ years old), ER status $(E R+/-)$, stage (early/late), or time since blood collection $(<5,5-$ $10,>10$ years) (data not shown). To account for possible subclinical effects from occult disease at the time of blood collection, we also investigated risk associations $<$ 2 years versus $\geq 2$ years since blood draw. We observed putative associations within 2 years of blood draw with cg00899463 (promoter of SGMS2, $q<10^{-8}$ ) and cg07145930 (promoter of G3BP1, $q=5.78 \times 10^{-5}$ ), but there was substantial heterogeneity across studies for both CpGs $\left(I^{2}=100 \%\right)$, with each association driven by a single study.

We next focused on CpGs and genes reported to be associated with breast cancer risk in previous studies. Of the $250 \mathrm{CpGs}$ reported by $\mathrm{Xu}$ et al. [26], 205 were included in our meta-analysis; we found no evidence of an association between these CpGs and breast cancer risk ( $q$ value $>0.17 ; q$ value calculation based on those 205 CpGs). Overall, methylation at the promoter region of $B R C A 1$ was not associated with breast cancer risk $(P=$ 0.88 ); of the 26 CpGs in this region that we examined, pooled ORs were consistent in direction with previous reports for 14, with cg20185525 having the largest OR $(\mathrm{OR}=1.11,95 \% \mathrm{CI}=0.99,1.25)$. With respect to gene RASSF1A, 43 CpGs were in its promoter region but only 7 of them were associated with breast cancer risk in the direction previously reported. Overall, there was no association with the promoter region of RASSF1A overall (enrichment $P=0.061$ ). Of the $9 \mathrm{CpG}$ sites located in the body of ATM, only two were associated with breast cancer risk in the direction previously reported and 
Table 1 Characteristics of the nested case-control studies included in the meta-analysis

\begin{tabular}{|c|c|c|c|c|}
\hline Characteristics & $\begin{array}{l}\text { Melbourne Collaborative } \\
\text { Cohort Study }\end{array}$ & $\begin{array}{l}\text { European Prospective Investigation } \\
\text { into Cancer and Nutrition (Italy) }\end{array}$ & $\begin{array}{l}\text { European Prospective Investigation } \\
\text { into Cancer and Nutrition (IARC) }\end{array}$ & $\begin{array}{l}\text { Prostate, Lung, Colorectal } \\
\text { and Ovarian Screening Trial }\end{array}$ \\
\hline Acronym & MCCS & EPIC-Italy & EPIC-IARC & PLCO \\
\hline Reference & (17) & (18) & (19) & - \\
\hline Location & Australia & Italy & $\begin{array}{l}\text { Germany, Greece, Italy, Spain, The } \\
\text { Netherlands, and the UK }\end{array}$ & US \\
\hline $\begin{array}{l}\text { Methylation array } \\
\text { used }\end{array}$ & HM450K & HM450K & HM450K & EPIC \\
\hline \multicolumn{5}{|c|}{ Number of subjects, $n$} \\
\hline $\begin{array}{l}\text { Controls }(N= \\
1926)\end{array}$ & 409 & 248 & 423 & 805 \\
\hline Cases $(N=1703)$ & 409 & 248 & 423 & 583 \\
\hline $\begin{array}{l}\text { Age at blood draw } \\
\text { (years), mean (SD) }\end{array}$ & $56.7(7.9)$ & $52.2(7.2)$ & $52.2(9.0)$ & $62.2(5.2)$ \\
\hline \multicolumn{5}{|c|}{ Time from blood draw to diagnosis in cases } \\
\hline Median (IQR) & $7.7(4.4 ., 11.1)$ & $6.55(2.5,10.6)$ & $7.7(5.0,10.3)$ & $8.4(5.6,10.5)$ \\
\hline Average (SD) & $7.6(3.9)$ & $6.7(4.4)$ & $7.5(3.2)$ & $7.9(3.5)$ \\
\hline \multicolumn{5}{|l|}{ ER status, $n(\%)$} \\
\hline Positive & $297(72.6)$ & $147(59.3)$ & $350(82.7)$ & $411(70.5)$ \\
\hline Negative & $103(25.2)$ & $30(12.0)$ & 73 (17.3) & 78 (12.9) \\
\hline \multicolumn{5}{|l|}{ Stage $^{\dagger}, n(\%)$} \\
\hline Early & $246(60.1)$ & 71 (28.6) & 207 (48.9) & 337 (57.8) \\
\hline Late & $141(34.5)$ & $40(16.1)$ & $95(22.5)$ & $183(31.4)$ \\
\hline
\end{tabular}

$S D$ standard deviation, $I Q R$ interquartile range, $E R$ estrogen receptor

${ }^{\dagger}$ Stage: a cancer was considered an early stage if it was classified as localized (EPIC-Italy, EPIC-IARC) or stage I (MCCS, PLCO). A cancer was considered late-stage if it was classified as regional or metastatic (EPIC-Italy, EPIC-IARC) or stages II, III, or IV (MCCS, PLCO)

there was no enrichment $(P=0.26)$. Previously identified CpGs in RPTOR (cg06418238), MGRN1 (cg00736299) and RAPSN (cg27466532) were not associated with breast cancer risk (cg06418238, $P=0.237, I^{2}=0 \%$; cg00736299, $P=0.779, I^{2}=58 \%$; cg27466532, $P=0.636$, $\left.I^{2}=0 \%\right)$.

\section{Associations between global methylation and breast cancer risk}

We found no evidence of an association between global methylation levels and breast cancer risk. We estimated an OR per one standard deviation increase in average methylation levels of 0.94 (95\% CI $0.85,1.05$;
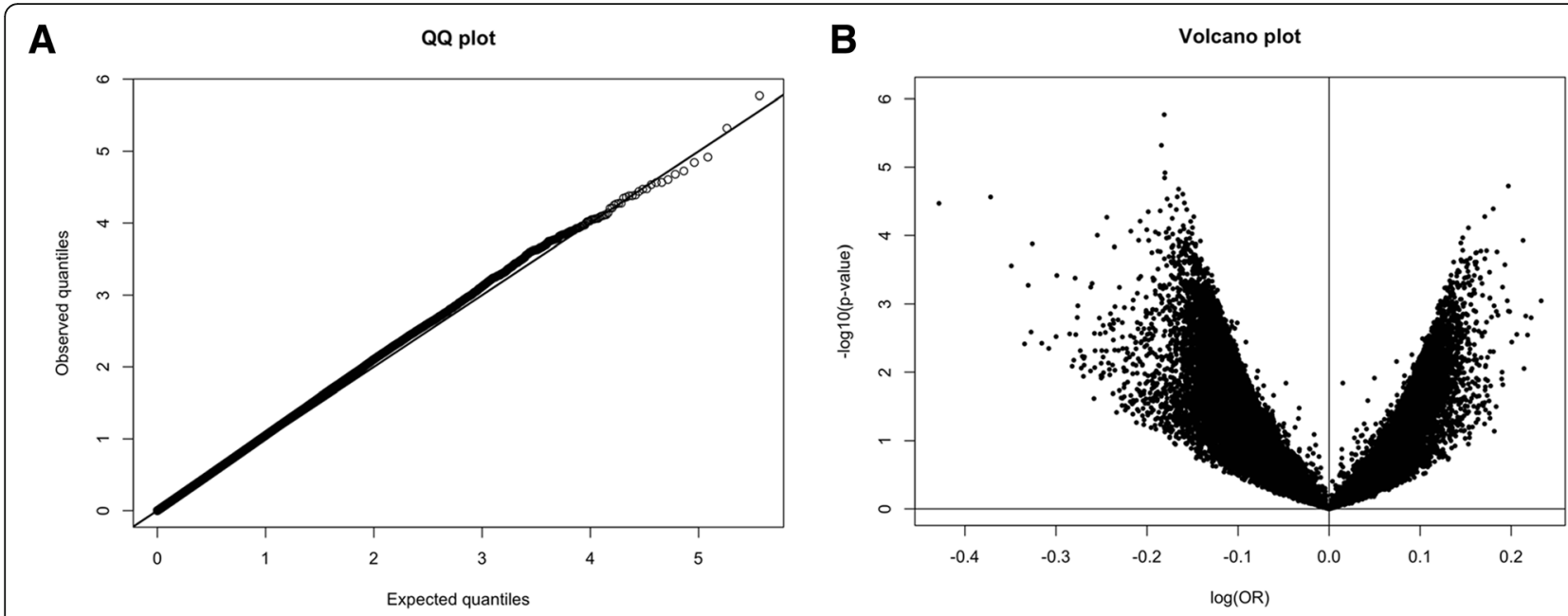

Fig. 1 Overall associations between methylation and breast cancer risk. QQ-plot (a) and a volcano plot (b) for the overall associations between methylation values at individual $\mathrm{CpG}$ sites and breast cancer risk 
$P=0.26 ; \quad P$ for study heterogeneity $=0.86 ; I^{2}=0 \%$; Fig. 2). Neither adding previously published results from the NOWAC study (Additional file 1: Figure S1) nor stratifying by age at blood draw, ER status or time since blood draw qualitatively changed the result (Table 2). Global methylation was associated with breast cancer risk in women diagnosed with late-stage disease when analyses were not adjusted for cell type $(\mathrm{OR}=0.83,95 \%$ CI $0.71,0.97)$, but not when cell types were included in the model $(\mathrm{OR}=0.96,95 \% \mathrm{CI}$ $0.79,1.13)$. Global methylation measures computed by the CpG region (island, shores, shelves, or open sea) were not associated with breast cancer risk. With respect to global methylation in CpG in promoters, a significant association was observed when the analysis was not adjusted for cell type, but it was not statistically significantly associated $(P=0.92)$ after adjustment (Table 2). Global methylation at other genomic regions, such as gene bodies, 3'UTR, or between genes, was not statistically significantly associated with breast cancer risk.

\section{Discussion}

No association between DNA methylation in blood and breast cancer risk was observed in this meta-analysis, either at individual sites or globally. Associations with CpG sites that had previously been reported to be differentially methylated between breast cancer cases and controls by smaller studies were not replicated by our larger study.

BRCA1 promoter methylation in blood has previously been reported to be higher in breast cancer patients compared with controls by some studies $[1-3,20]$, but not others $[17,18,21]$. In our study, we found no evidence of an association between BRCA1 methylation and breast cancer risk. It is important to note that blood collection in many of these previous studies was done at the time of cancer diagnosis, so DNA methylation could have been affected by the developing tumor; other studies included BRCA1 mutation carriers that were oversampled/represented in the cases but not in the controls. This differs from this meta-analysis in which all studies were prospective and did not select on family history (less than $20 \%$ of participants reported having a family history of breast cancer in the PLCO, which was the only one of the four cohorts with available information). When analyses were restricted to subjects with a family history of breast cancer (108 cases and 107 controls), no significant association was observed. In addition, the assays used in the aforementioned studies were mostly based on targeted regions, for which a single measurement of methylation for an entire genomic region is obtained, and not genome-wide array-based assays, as in our study, for which methylation measurements are performed at individual CpG sites. However, we conducted enrichment tests and still did not observe associations. Similar results were observed for RASSF1A, despite previously reported associations [22, 42-44].

A few studies have reported hypermethylation of repetitive elements within the body of $A T M$ to be associated with breast cancer risk $[4,15]$. None of the CpG sites in $A T M$ were statistically significantly associated with breast cancer risk in our study. However, the HM450 assay used in our analysis is gene-centered, with

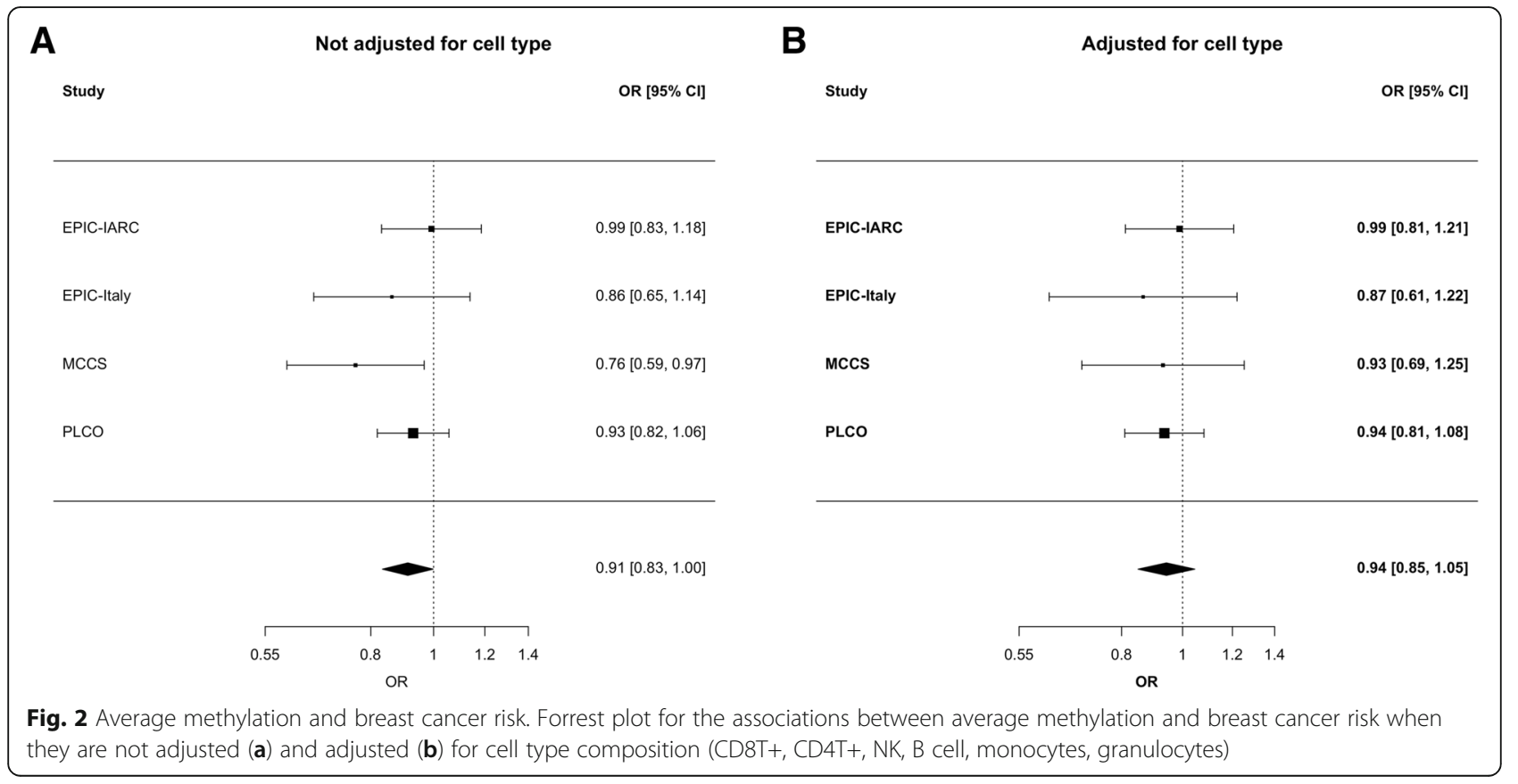


Table 2 Stratified analysis of average methylation levels and breast cancer risk by several characteristics

\begin{tabular}{|c|c|c|c|c|c|c|c|c|c|c|}
\hline Characteristics & $O R^{*}$ & $95 \% \mathrm{Cl}^{*}$ & $P$ value ${ }^{*}$ & $P$ hete & $P^{2}$ (95\% uncer. int.) & $\mathrm{OR}^{\S}$ & $95 \% \mathrm{Cl}^{\S}$ & $P$ value $^{\S}$ & $P$ hete & $P^{2}$ (95\% uncer. int.) \\
\hline \multicolumn{11}{|c|}{ Age at blood draw (years) } \\
\hline$<50$ & 1.11 & $(0.82,1.50)$ & 0.49 & 0.17 & $0.0(0.0,89.5)$ & 1.04 & $(0.72,1.51)$ & 0.82 & 0.57 & $0.0(-)$ \\
\hline$\geq 50$ & 0.89 & $(0.81,0.99)$ & 0.03 & & $0.0(0.0,75.8)$ & 0.93 & $(0.84,1.04)$ & 0.22 & & $0.0(0.0,0.0)$ \\
\hline \multicolumn{11}{|l|}{ ER status } \\
\hline ER+ & 0.92 & $(0.83,1.02)$ & 0.10 & 0.88 & $0.0(0.0,66.1)$ & 0.93 & $(0.83,1.05)$ & 0.25 & 0.46 & $0.07(0.0,0.0)$ \\
\hline ER- & 0.93 & $(0.76,1.15)$ & 0.51 & & $40.5(0.0,79.9)$ & 1.04 & $(0.81,1.34)$ & 0.77 & & $0.0(0.0,83.8)$ \\
\hline \multicolumn{11}{|l|}{ Stage $^{\dagger}$} \\
\hline Early & 0.94 & $(0.84,1.06)$ & 0.34 & 0.20 & $0.0(0.0,76.0)$ & 0.90 & $(0.79,1.03)$ & 0.13 & 0.68 & $0.0(0.0,72.4)$ \\
\hline Late & 0.83 & $(0.71,0.97)$ & 0.02 & & $9.7(0.0,86.2)$ & 0.95 & $(0.79,1.13)$ & 0.55 & & $0.0(0.0,80.5)$ \\
\hline \multicolumn{11}{|l|}{ Time since diagnosis } \\
\hline$<2$ years & 0.96 & $(0.75,1.24)$ & 0.78 & 0.68 & $11.4(0.0,86.4)$ & 0.99 & $(0.72,1.37)$ & 0.96 & 0.80 & $0.0(0.0,77.4)$ \\
\hline$\geq 2$ years & 0.91 & $(0.83,1.00)$ & 0.06 & & $24.9(0.0,88.3)$ & 0.95 & $(0.85,1.06)$ & 0.34 & & $0.0(0.0,26.5)$ \\
\hline \multicolumn{11}{|l|}{ Time since diagnosis } \\
\hline$<5$ years & 0.93 & $(0.78,1.10)$ & 0.39 & 0.98 & $71.4(18.6,90.0)$ & 0.93 & $(0.75,1.14)$ & 0.47 & 0.99 & $19.4(0.0,87.7)$ \\
\hline$\geq 5$ and $\leq 10$ years & 0.92 & $(0.81,1.04)$ & 0.20 & & $0.0(0.0,71.3)$ & 0.94 & $(0.81,1.08)$ & 0.37 & & $0.0(0.0,74.0)$ \\
\hline$>10$ years & 0.94 & $(0.80,1.11)$ & 0.46 & & $0.0(0.0,56.2)$ & 0.93 & $(0.77,1.12)$ & 0.46 & & $0.0(0.0,70.6)$ \\
\hline \multicolumn{11}{|l|}{ CpG region $^{\ddagger}$} \\
\hline CpG island & 0.93 & $(0.85,1.02)$ & 0.13 & 0.98 & $0.0(0.0,79.6)$ & 0.98 & $(0.87,1.10)$ & 0.74 & 0.95 & $0.0(0.0,71.1)$ \\
\hline CpG shore & 0.92 & $(0.84,1.00)$ & 0.06 & & $0.0(0.0,23.0)$ & 0.94 & $(0.84,1.04)$ & 0.23 & & $0.0(0.0,0.0)$ \\
\hline CpG shelf & 0.94 & $(0.86,1.03)$ & 0.20 & & $58.7(0.0,86.3)$ & 0.96 & $(0.86,1.06)$ & 0.42 & & $0.0(0.0,27.1)$ \\
\hline Open sea & 0.94 & $(0.86,1.03)$ & 0.18 & & $62.3(0.0,87.3)$ & 0.95 & $(0.85,1.05)$ & 0.31 & & $0.0(0.0,60.9)$ \\
\hline \multicolumn{11}{|l|}{ Regulatory region" } \\
\hline Promoter & 0.90 & $(0.82,0.99)$ & 0.03 & 0.95 & $0.0(0.0,65.5)$ & 0.93 & $(0.83,1.04)$ & 0.20 & 0.96 & $0.0(0.0,64.0)$ \\
\hline Gene body & 0.93 & $(0.85,1.02)$ & 0.14 & & $48.1(0.0,82.8)$ & 0.96 & $(0.87,1.07)$ & 0.46 & & $0.0(0.0,62.3)$ \\
\hline 3'UTR & 0.93 & $(0.85,1.02)$ & 0.12 & & $59.8(0.0,86.6)$ & 0.96 & $(0.87,1.07)$ & 0.50 & & $0.0(0.0,50.8)$ \\
\hline Intergenic & 0.92 & $(0.84,1.01)$ & 0.07 & & $53.7(0.0,84.7)$ & 0.94 & $(0.85,1.04)$ & 0.27 & & $0.0(0.0,64.4)$ \\
\hline
\end{tabular}

The $I^{2}$ statistic estimates (in percent) how much of the total variability in the effect size estimates (which is composed of heterogeneity and sampling variability) can be attributed to heterogeneity among the true effects. $I^{2}$ varies from 0 to $100 \%$

$P$ heterogeneity: Tests whether the variability in the observed effect sizes across strata is larger than would be expected based on sampling variability alone

${ }^{\dagger}$ Stage: a cancer was considered an early stage if it was classified as localized (EPIC-Italy, EPIC-IARC) or stage I (MCCS, PLCO). A cancer was considered late-stage if it was classified as regional or metastatic (EPIC-Italy, EPIC-IARC) or stages II, III, or IV (MCCS, PLCO)

${ }^{\ddagger} \mathrm{CpG}$ region: shore $0-2 \mathrm{~kb}$ from $\mathrm{CpG}$ island, shelf $=2-4 \mathrm{~kb}$ from $\mathrm{CpG}$ island, OpenSea $>4 \mathrm{~kb}$ from CpG island

"Based on the UCSC classification. CpGs in promoter: CpGs located in TSS200, TSS1500, 5'UTR, or exon 1 (TSS transcription start site)

*Adjusted for all variables except for cell type. ${ }^{5}$ Adjusted for all variables and cell type (CD8T+, CD4T+, NK, B cell, monocytes, granulocytes)

a special focus on gene promoters, and has less coverage of other areas of the genome, particularly repetitive elements. Our analysis included only nine CpG sites in the body of $A T M$ so that we could not thoroughly assess gene-body methylation.

Previous findings for cg06418238 in RPTOR, cg00736299 in MGRN1, and cg27466532 in RAPSN that were recently reported to be associated with breast cancer risk [22] were not replicated by our study. One of the cohorts included in the meta-analysis (MCCS) had previously published the lack of replication of the CpG sites [24], and this was confirmed by this meta-analysis.
A previous analysis of the Sister Study reported a methylation signature for breast cancer consisting of 250 differentially methylated $\mathrm{CpG}$ sites in blood identified in a prospective study of 298 cases and 612 cancer-free women [26]. We found no evidence of association with risk for the $205 \mathrm{CpG}$ sites we could examine in our larger study. A number of differences between the two studies could potentially explain the discrepant findings. First, the Sister Study was enriched for family history, with all cases and controls being relatives of breast cancer cases, whereas the four cohorts included in the meta-analysis were sampled from the general population. Another difference is that the average time from blood 
draw to diagnosis for cases in the Sister Study was 1.3 years, suggesting that some of these women may have been developing breast cancer at the time of blood draw. The average time to diagnosis for the cases in our study was over 5 years. None of the sites reported by the Sister Study were associated with risk. We also performed a sensitivity analysis to rule out the influence of potential subclinical disease.

There was no association between global DNA methylation and breast cancer risk in our meta-analysis. Previously, two of the cohorts (MCCS and EPIC-Italy) included in our study reported significant associations with breast cancer risk [23, 30]. However, EPIC-Italy included additional case-control pairs for the present analysis (248 pairs compared to 162 pairs in the previous publication [30]), and in this study, the association was no longer significant. Only one of the cohorts (MCCS) included in the meta-analysis showed a significant association, similar to their previously result, but only when the analysis was not adjusted for cell-type composition. No evidence of association was observed individually in either of the two largest, unpublished studies included in this meta-analysis (EPIC-IARC and PLCO), as was the case in the NOWAC study [30].

Previous studies that assessed associations between global DNA methylation and breast cancer risk have reached mixed conclusions. Global methylation (percentage of 5-methyldeoxycytosine, i.e., \%5-dmC, with respect to the total cytosine content) was measured using different methods, at different genomic locations (LINE-1, CmCGG common in promoters, etc.), and various populations and study designs (retrospective versus prospective) were used, which makes it difficult to compare results. Several studies have also suggested that blood global hypomethylation is associated with increased cancer risk in general [9, 45-47], not necessarily just breast cancer risk. The reasons for any such association are not clear, but it may represent changes in the regulation of methyl transfer reactions due to age or certain exposures (residual confounding), the presence of the cancer years before diagnosis, circulating tumor DNA, or a false positive.

Our analysis has several strengths. First, it is the largest evaluation to date of blood DNA methylation and breast cancer risk. The large sample allowed us not only to investigate new associations, but also to test associations previously reported by smaller studies. Another important aspect of our analysis is the prospective design of all the studies included, which avoids the influence of reverse causation (methylation changes due to the presence of cancer), as well as potential effects on blood methylation of treatment given prior to blood collection. Our analysis also has some limitations. First, we had limited statistical power to detect small effects of methylation on breast cancer risk, despite having a sample size which was larger than that of previous studies which reported significant associations. Another limitation is that we restricted the analysis to sites in the Illumina HM450 BeadChip, which accounts for less than $2 \%$ of the 28 million CpG sites in the genome [48]. This array is also gene-centered and particularly lacks coverage in intergenic regions. Therefore, our analysis may have missed genomic regions that could be relevant to breast cancer risk. Finally, DNA methylation is cell-specific, and therefore, average methylation levels in blood cells could reflect cell heterogeneity by case-control status. None of the included studies had collected information on direct blood cell types, so we used a standard algorithm to infer blood cell counts and account for this source of heterogeneity.

\section{Conclusions}

In summary, we found no evidence in this meta-analysis of four prospective cohort studies that DNA methylation measured in blood is associated with substantial variation in breast cancer risk. Larger studies may be required to determine if modest to weak associations exist between blood DNA methylation and breast cancer risk. Studies with greater methylation coverage of the genome may also have the potential to uncover novel associations.

\section{Additional file}

Additional file 1: Description of the four prospective studies. Also, a figure with the results of the association between average methylation and breast cancer, adding published data from the NOWAC study. (DOCX $126 \mathrm{~kb})$

\section{Funding}

This research was partially supported by the Intramural Research Program of the National Institutes of Health, National Cancer Institute, Division of Cancer Epidemiology and Genetics. The work performed by the Epigenetics Group at IARC was supported by grants from the Institut National du Cancer (INCa, France), the European Commission (EC) Seventh Framework Programme (FP7) Translational Cancer Research (TRANSCAN) Framework, the Fondation ARC pour la Recherche sur le Cancer (France), and la Ligue Nationale (Française) Contre le Cancer to ZH. The MCCS methylation work was supported by the National Health and Medical Research Council (grant number 1011618) and the Victorian Breast Cancer Research Consortium. The work performed at Imperial College London was funded by the Breast Cancer Now and supported by the Cancer Research UK Imperial Centre.

Availability of data and materials

Meta-analysis results will be available at dbGAP.

\section{Authors' contributions}

$C B, S A, P A D, A J, J N S, Z H, J M F, R L M$, and MGC conceived the study and wrote the manuscript. $C B, S A, P A D$, and $A J$ conducted the statistical analysis. $B H, E K$ $A H, C C, V C, M C S, I R, G G G, D E, S P, M A, L B, P V$, and GS contributed the data and made critical comments on the manuscript. All authors read and approved the final manuscript.

Ethics approval and consent to participate

The following Institutional Review Boards (IRBs) have approved the collection of different datasets, which have contributed to this study: Cancer Council 
Victoria's Human Research Committee, International Agency for Research on Cancer (IARC), and the US National Cancer Institute and participating individual centers for each study.

\section{Consent for publication}

Not applicable.

\section{Competing interests}

The authors declare that they have no competing interests.

\section{Publisher's Note}

Springer Nature remains neutral with regard to jurisdictional claims in published maps and institutional affiliations.

\section{Author details}

'Divison of Cancer Epidemiology and Genetics, National Cancer Institute, Bethesda, USA. ${ }^{2}$ International Agency for Research on Cancer (IARC), Lyon, France. ${ }^{3}$ AMCHSS, Sree Chitra Tirunal Institute for Medical Sciences and Technology, Trivandrum, India. ${ }^{4}$ Cancer Epidemiology and Intelligence Division, Cancer Council Victoria, Melbourne, Victoria, Australia. ${ }^{5}$ Centre for Epidemiology and Biostatistics, Melbourne School of Population and Global Health, The University of Melbourne, Melbourne, Victoria, Australia. ${ }^{6}$ Division of Cancer, Imperial College London, London, UK. ${ }^{7}$ Cancer Genomics Research Laboratory, Leidos Biomedical Research, Inc., Frederick National Laboratory for Cancer Research, Frederick, USA. ${ }^{8}$ Genetic Epidemiology Laboratory, Department of Pathology, The University of Melbourne, Parkville, Australia. ${ }^{9}$ IIGM (Italian Institute for Genomic Medicine), Turin, Italy. ${ }^{10}$ Department of Medical Sciences, University of Turin, Turin, Italy. ${ }^{11}$ Department of Clinical and Experimental Medicine, University of Pisa, Pisa, Italy. ${ }^{12}$ MRC-PHE Center for Environment and Health, School of Public Health, Imperial College, London, UK. ${ }^{13}$ CESP (U1018 INSERM, Équipe Générations et Santé), Facultés de médecine Université Paris-Sud, UVSQ, Université Paris-Saclay, Villejuif, France.

Received: 15 January 2019 Accepted: 23 April 2019

Published online: 17 May 2019

\section{References}

1. Snell C, Krypuy M, Wong EM, KConFab Investigators, Loughrey MB, Dobrovic A. BRCA1 promoter methylation in peripheral blood DNA of mutation negative familial breast cancer patients with a BRCA1 tumour phenotype. Breast Cancer Res. 2008;10(1):R12.

2. Wong EM, Southey MC, Fox SB, Brown MA, Dowty JG, Jenkins MA, Giles GG, Hopper JL, Dobrovic A. Constitutional methylation of the BRCA1 promoter is specifically associated with BRCA1 mutation-associated pathology in early-onset breast Cancer. Cancer Prev Res. 2011;4(1):23-33.

3. Iwamoto T, Yamamoto N, Taguchi T, Tamaki Y, Noguchi S. BRCA1 promoter methylation in peripheral blood cells is associated with increased risk of breast cancer with BRCA1 promoter methylation. Breast Cancer Res Treat. 2011;129(1):69-77.

4. Brennan K, Garcia-Closas M, Orr N, Fletcher O, Jones M, Ashworth A, Swerdlow A, Thorne H, Riboli E, Vineis $\mathrm{P}$, et al. Intragenic ATM methylation in peripheral blood DNA as a biomarker of breast Cancer risk. Cancer Res. 2012;72(9):2304-13.

5. Ulrich CM, Toriola AT, Koepl LM, Sandifer T, Poole EM, Duggan C, McTiernan A, Issa J-PJ. Metabolic, hormonal and immunological associations with global DNA methylation among postmenopausal women. Epigenetics. 2012;7(9):1020-8.

6. Shenker NS, Flower KJ, Wilhelm-Benartzi CS, Dai W, Bell E, Gore E, El Bahrawy M, Weaver G, Brown R, Flanagan JM. Transcriptional implications of intragenic DNA methylation in the oestrogen receptor alpha gene in breast cancer cells and tissues. BMC Cancer. 2015;15:337.

7. Liu C, Marioni RE, Hedman AK, Pfeiffer L, Tsai PC, Reynolds LM, Just AC, Duan Q, Boer CG, Tanaka T, et al. A DNA methylation biomarker of alcohol consumption. Mol Psychiatry. 2016;23(2):422-33.

8. Wahl S, Drong A, Lehne B, Loh M, Scott WR, Kunze S, Tsai PC, Ried JS, Zhang W, Yang Y, et al. Epigenome-wide association study of body mass index, and the adverse outcomes of adiposity. Nature. 2017;541(7635):81-6.

9. Brennan K, Flanagan JM. Is there a link between genome-wide hypomethylation in blood and cancer risk? Cancer Prev Res (Phila). 2012; 5(12):1345-57.
10. Baglietto L, Ponzi E, Haycock P, Hodge A, Bianca Assumma M, Jung CH, Chung J, Fasanelli F, Guida F, Campanella G, et al. DNA methylation changes measured in pre-diagnostic peripheral blood samples are associated with smoking and lung cancer risk. Int J Cancer. 2017;140(1): 50-61.

11. Shenker NS, Ueland PM, Polidoro S, van Veldhoven K, Ricceri F, Brown R, Flanagan JM, Vineis P. DNA methylation as a Long-term biomarker of exposure to tobacco smoke. Epidemiology. 2013;24(5):712-6.

12. Miousse IR, Kutanzi KR, Koturbash I. Effects of ionizing radiation on DNA methylation: from experimental biology to clinical applications. Int J Radiat Biol. 2017;93(5):457-69.

13. Johansson A, Flanagan JM. Epigenome-wide association studies for breast cancer risk and risk factors. Trends Cancer Res. 2017;12:19-28.

14. Tang Q, Cheng J, Cao X, Surowy H, Burwinkel B. Blood-based DNA methylation as biomarker for breast cancer: a systematic review. Clin Epigenetics. 2016;8(1):115.

15. Flanagan JM, Munoz-Alegre M, Henderson S, Tang T, Sun P, Johnson N, Fletcher O, Dos Santos SI, Peto J, Boshoff C, et al. Gene-body hypermethylation of ATM in peripheral blood DNA of bilateral breast cancer patients. Hum Mol Genet. 2009;18(7):1332-42.

16. Iwamoto T, Yamamoto N, Taguchi T, Tamaki Y, Noguchi S. BRCA1 promoter methylation in peripheral blood cells is associated with increased risk of breast cancer with BRCA1 promoter methylation. Breast Cancer Res Treat. 2010;129(1):69-77.

17. Cho YH, Yazici H, Wu HC, Terry MB, Gonzalez K, Qu M, Dalay N, Santella RM. Aberrant promoter hypermethylation and genomic hypomethylation in tumor, adjacent normal tissues and blood from breast cancer patients. Anticancer Res. 2010;30(7):2489-96.

18. Bosviel R, Garcia S, Lavediaux G, Michard E, Dravers M, Kwiatkowski F, Bignon Y-J, Bernard-Gallon DJ. BRCA1 promoter methylation in peripheral blood DNA was identified in sporadic breast cancer and controls. Cancer Epidemiol. 2012;36(3):e177-82.

19. Zhang L, Long X. Association of BRCA1 promoter methylation with sporadic breast cancers: evidence from 40 studies. Sci Rep. 2015;5:17869.

20. Gupta S, Jaworska-Bieniek K, Narod SA, Lubinski J, Wojdacz TK, Jakubowska A. Methylation of the BRCA1 promoter in peripheral blood DNA is associated with triple-negative and medullary breast cancer. Breast Cancer Res Treat. 2014;148(3):615-22.

21. Cho YH, McCullough LE, Gammon MD, Wu HC, Zhang YJ, Wang Q, Xu X, Teitelbaum SL, Neugut Al, Chen J, et al. Promoter Hypermethylation in white blood cell DNA and breast Cancer risk. J Cancer. 2015;6(9):819-24.

22. Tang Q, Holland-Letz T, Slynko A, Cuk K, Marme F, Schott S, Heil J, Qu $B$, Golatta $M$, Bewerunge-Hudler $M$, et al. DNA methylation array analysis identifies breast cancer associated RPTOR, MGRN1 and RAPSN hypomethylation in peripheral blood DNA. Oncotarget. 2016;7(39): 64191-202.

23. Severi G, Southey MC, English DR. Jung C-h, Lonie a, McLean C, Tsimiklis H, Hopper JL, Giles GG, Baglietto L: epigenome-wide methylation in DNA from peripheral blood as a marker of risk for breast cancer. Breast Cancer Res Treat. 2014;148(3):665-73.

24. Dugué P-A, Milne RL, Southey MC. A prospective study of peripheral blood DNA methylation at RPTOR, MGRN1 and RAPSN and risk of breast cancer. Breast Cancer Res Treat. 2017;161(1):181-3.

25. Joo JE, Dowty JG, Milne RL, Wong EM, Dugue PA, English D, Hopper JL, Goldgar DE, Giles GG, Southey MC, et al. Heritable DNA methylation marks associated with susceptibility to breast cancer. Nat Commun. 2018;9(1):867.

26. Xu Z, Bolick SCE, DeRoo LA, Weinberg CR, Sandler DP, Taylor JA. Epigenome-wide association study of breast Cancer using prospectively collected sister study samples. J Natl Cancer Inst. 2013;105(10):694-700.

27. Vryer R, Saffery R. What's in a name? Context-dependent significance of 'global' methylation measures in human health and disease. Clin Epigenetics. 2017;9(1):2.

28. Jones PA, Gonzalgo ML. Altered DNA methylation and genome instability: a new pathway to cancer? Proc Natl Acad Sci. 1997;94(6):2103-5.

29. Sturgeon SR, Pilsner JR, Arcaro KF, Ikuma K, Wu H, Kim SM, ChopraTandon N, Karpf AR, Ziegler RG, Schairer C, et al. White blood cell DNA methylation and risk of breast cancer in the prostate, lung, colorectal, and ovarian Cancer screening trial (PLCO). Breast cancer research : BCR. 2017;19(1):94.

30. van Veldhoven K, Polidoro S, Baglietto L, Severi G, Sacerdote C, Panico S, Mattiello A, Palli D, Masala G, Krogh V, et al. Epigenome-wide association 
study reveals decreased average methylation levels years before breast cancer diagnosis. Clin Epigenetics. 2015;7(1):67.

31. Ambatipudi S, Horvath S, Perrier F, Cuenin C, Hernandez-Vargas H, Le Calvez-Kelm F, Durand G, Byrnes G, Ferrari P, Bouaoun L, et al. DNA methylome analysis identifies accelerated epigenetic ageing associated with postmenopausal breast cancer susceptibility. Eur J Cancer. 2017;75:299-307.

32. Prorok PC, Andriole GL, Bresalier RS, Buys SS, Chia D, Crawford ED, Fogel R, Gelmann EP, Gilbert F, Hasson MA, et al. Design of the Prostate, lung, colorectal and ovarian (PLCO) Cancer screening trial. Control Clin Trials. 2000;21(6 Suppl):273S-309S.

33. Moran S, Arribas C, Esteller M. Validation of a DNA methylation microarray for $850,000 \mathrm{CpG}$ sites of the human genome enriched in enhancer sequences. Epigenomics. 2016;8(3):389-99.

34. Aryee MJ, Jaffe AE, Corrada-Bravo H, Ladd-Acosta C, Feinberg AP, Hansen KD, Irizarry RA. Minfi: a flexible and comprehensive Bioconductor package for the analysis of Infinium DNA methylation microarrays. Bioinformatics. 2014;30(10):1363-9.

35. Maksimovic J, Gordon L, Oshlack A. SWAN: subset-quantile within Array normalization for Illumina Infinium HumanMethylation450 BeadChips. Genome Biol. 2012;13(6):R44

36. Pidsley R, Zotenko E, Peters TJ, Lawrence MG, Risbridger GP, Molloy P, Van Djik S, Muhlhausler B, Stirzaker C, Clark SJ. Critical evaluation of the Illumina MethylationEPIC BeadChip microarray for whole-genome DNA methylation profiling. Genome Biol. 2016;17(1):208.

37. Chen YA, Lemire M, Choufani S, Butcher DT, Grafodatskaya D, Zanke BW, Gallinger S, Hudson TJ, Weksberg R. Discovery of cross-reactive probes and polymorphic CpGs in the Illumina Infinium HumanMethylation450 microarray. Epigenetics. 2013;8(2):203-9.

38. Houseman EA, Accomando WP, Koestler DC, Christensen BC, Marsit CJ, Nelson HH, Wiencke JK, Kelsey KT. DNA methylation arrays as surrogate measures of cell mixture distribution. BMC Bioinformatics. 2012;13(1):86.

39. Leek JT, Storey JD. Capturing heterogeneity in gene expression studies by surrogate variable analysis. PLoS Genet. 2007;3(9):1724-35.

40. Leek JT, Storey JD. A general framework for multiple testing dependence. Proc Natl Acad Sci. 2008;105(48):18718-23.

41. Sandoval J, Heyn H, Moran S, Serra-Musach J, Pujana MA, Bibikova M, Esteller M. Validation of a DNA methylation microarray for 450,000 CpG sites in the human genome. Epigenetics. 2011;66):692-702.

42. Kloten V, Becker B, Winner K, Schrauder MG, Fasching PA, Anzeneder T, Veeck J, Hartmann A, Knüchel R, Dahl E. Promoter hypermethylation of the tumor-suppressor genes ITIH5, DKK3, and RASSF1A as novel biomarkers for blood-based breast cancer screening. Breast Cancer Res. 2013;15(1):R4.

43. Yazici $H$, Terry MB, Cho YH, Senie RT, Liao Y, Andrulis I, Santella RM. Aberrant methylation of $<$ em>RASSF1A</em $>$ in plasma DNA before breast Cancer diagnosis in the breast Cancer family registry. Cancer epidemiology biomarkers \&amp. Prevention. 2009;18(10):2723-5.

44. Cao X, Tang Q, Holland-Letz T, Gundert M, Cuk K, Schott S, Heil J, Golatta M, Sohn C, Schneeweiss A, et al. Evaluation of promoter methylation of RASSF1A and ATM in peripheral blood of breast Cancer patients and healthy control individuals. Int J Mol Sci. 2018;19(3).

45. Woo HD, Kim J. Global DNA Hypomethylation in peripheral blood leukocytes as a biomarker for Cancer risk: a meta-analysis. PLoS One. 2012; 7(4):e34615.

46. FitzGerald LM, Naeem $H$, Makalic E, Schmidt DF, Dowty JG, Joo JE, Jung $C H$, Bassett JK, Dugue PA, Chung J, et al. Genome-wide measures of peripheral blood Dna methylation and prostate Cancer risk in a prospective nested case-control study. Prostate. 2017;77(5):471-8.

47. Dugue PA, Brinkman MT, Milne RL, Wong EM, FitzGerald LM, Bassett JK, Joo JE, Jung CH, Makalic E, Schmidt DF, et al. Genome-wide measures of DNA methylation in peripheral blood and the risk of urothelial cell carcinoma: a prospective nested case-control study. Br J Cancer. 2016;115(6):664-73.

48. Stirzaker C, Taberlay PC, Statham AL, Clark SJ. Mining cancer methylomes: prospects and challenges. Trends Genet. 2014;30(2):75-84.

\section{Ready to submit your research? Choose BMC and benefit from:}

- fast, convenient online submission

- thorough peer review by experienced researchers in your field

- rapid publication on acceptance

- support for research data, including large and complex data types

- gold Open Access which fosters wider collaboration and increased citations

- maximum visibility for your research: over $100 \mathrm{M}$ website views per year

At BMC, research is always in progress.

Learn more biomedcentral.com/submissions 